\title{
MRI compared to conventional diagnostic work-up in the detection and evaluation of invasive lobular carcinoma of the breast: a review of existing literature
}

\author{
Ritse M. Mann • Yvonne L. Hoogeveen • \\ Johan G. Blickman · Carla Boetes
}

Received: 17 January 2007 / Accepted: 19 January 2007 / Published online: 15 February 2007

(C) Springer Science+Business Media B.V. 2007

\begin{abstract}
Purpose: The clinical diagnosis and management of invasive lobular carcinoma (ILC) of the breast presents difficulties. Magnetic resonance imaging (MRI) has been proposed as the imaging modality of choice for the evaluation of ILC. Small studies addressing different aspects of MRI in ILC have been presented but no large series to date. To address the usefulness of MRI in the work-up of ILC, we performed a review of the currently published literature.

Materials and methods: We performed a literature search using the query "lobular AND (MRI OR MR OR MRT OR magnetic)" in the Cochrane library, PubMed and scholar.google.com, to retrieve all articles that dealt with the use of MRI in patients with ILC. We addressed sensitivity, morphologic appearance, correlation with pathology, detection of additional lesions, and impact of MRI on surgery as different endpoints. Whenever possible we performed metaanalysis of the pooled data.

Results: Sensitivity is $93.3 \%$ and equal to overall sensitivity of MRI for malignancy in the breast. Morphologic appearance is highly heterogeneous and probably
\end{abstract}

R. M. Mann $(\varangle)$ · Y. L. Hoogeveen

J. G. Blickman · C. Boetes

Radiology, University Medical Center Nijmegen,

Geert Grooteplein 10, Nijmegen 6500 HB, The Netherlands

e-mail: r.mann@rad.umcn.nl

Y. L. Hoogeveen

e-mail: y.hoogeveen @rad.umcn.nl

J. G. Blickman

e-mail: j.blickma@rad.umcn.nl

C. Boetes

e-mail: c.boetes@rad.umcn.nl heavily influenced by interreader variability. Correlation with pathology ranges from 0.81 to 0.97 ; overestimation of lesion size occurs but is rare. In $32 \%$ of patients, additional ipsilateral lesions are detected and in $7 \%$ contralateral lesions are only detected by MRI. Consequently, MRI induces change in surgical management in $28.3 \%$ of cases.

Conclusion: This analysis indicates MRI to be valuable in the work-up of ILC. It provides additional knowledge that cannot be obtained by conventional imaging modalities which can be helpful in patient treatment.

Keywords Invasive lobular carcinoma of the breast . Magnetic resonance imaging · Sensitivity · Morphology · Additional findings $\cdot$ Impact on treatment

\section{Introduction}

Invasive lobular carcinoma (ILC) is the second most common histologic type of breast carcinoma after invasive ductal carcinoma (IDC). In most series ILC constitutes between 5 and $15 \%$ of all breast cancers, whereas IDC constitutes between 70 and $90 \%$ of all breast cancers [1-5]. Probably due to the use of complete hormone replacement therapy the lobular breast cancer component has continuously increased over the past decade from $9.5 \%$ in 1987 to $15.6 \%$ in 1999 [3].

Patients are, according to most series, a little older than patients presenting with IDC, especially the fraction of patients presenting with ILC younger than 40 is smaller [1, 5, 6]. Furthermore, the mean tumor size of ILC is slightly larger than in patients with IDC and patient presentation with a tumor larger than $5 \mathrm{~cm}$ occurs more often in cases of ILC [1, 5, 7]. 
Histopathologically, ILC are clearly defined: ILCs are constituted from small, relatively uniform cells, very similar to normal endothelial cells. Characteristically, these cells are only loosely cohesive and infiltrate the stroma in single cell file strands along ductuli. This growth pattern, present in $30-77 \%$ of cases [8], is also known as "Indian filing." It is probably caused by a typical loss of the adhesion molecule E-cadherin. Often there is very little desmoplastic stromal reaction $[8,9]$. The biological characteristics of ILC are usually less alarming than those of IDC: more tumors contain estrogen receptors and progesterone receptors, while expression of Her2/Neu and p53 are more often normal and axillary lymph nodes are not more often positive, even though ILC are overall larger in size than IDC $[1,7]$.

Probably due to the diffuse infiltrative growth pattern, ILC is frequently missed on mammography [5]. Detection is also compromised because ILC often has a density less than or equal to normal fibroglandular breast tissue on mammography $[5,10]$.

For correct treatment of ILC, adequate staging is important. Both mammography and ultrasound tend to underestimate lesion size and are therefore not optimal for staging purposes $[5,11]$. This may in part be the reason that higher failure rates of breastconserving therapy (BCT) in ILC than in IDC are reported [2, 11, 12]. Various authors therefore propose magnetic resonance imaging (MRI) as the modality of choice for the evaluation of ILC. Several small studies addressing the different aspects of the use of MRI in ILC have been presented, but no large series to date. Therefore many questions regarding the use of MRI in ILC remain unanswered.

1. The sensitivity of MRI for breast lesions is approximately $95-98 \%$, however, whether this holds true for ILC as well is not clear [13].

2. The morphologic aspects of ILC are not yet well defined, nor is the dynamic behavior of contrast agents in these tumors clearly documented.

3. Moreover, whether the MRI findings are similar to pathologic findings and can thus be used for accurate staging still needs to be established.

4. Finally, the impact of MRI on surgical treatment of ILC should be evaluated.

To answer these questions we performed a thorough review of the existing literature regarding the use of MRI in case of ILC and performed meta-analysis whenever possible. We subsequently reviewed the literature on other imaging modalities for this indication in order to evaluate the use of MRI from a clinical perspective.

\section{Materials and methods}

\section{Search strategy}

We performed a literature search for articles that specifically dealt with the use of MRI in patients with histologic proof of ILC published before 1 April 2006. The Cochrane Library, MEDLINE and the in-progress citations as provided by PubMed were searched using the query: "lobular AND (MR OR MRI OR MRT OR magnetic)." These databases were further searched using the "Related Articles" function in PubMed. The same query was used to browse the web using scholar.google.com.

Furthermore, the references of all retrieved articles were manually searched for relevant cross-references. Articles in all languages were accepted. All retrieved articles were then compared and from overlapping series of patients only the most recent publication was accepted.

Many different search terms were used for literature review of other imaging modalities. However, only PubMed was used as search engine.

\section{Endpoints}

The study was thus undertaken to answer the following four questions.

1. What is the sensitivity of MRI for ILC?

2. What are the visual characteristics of ILC on MRI?

3. Are the findings on MRI equal to the findings at pathology?

4. What is the impact of MRI on surgical management of ILC?

Whenever studies allowed direct comparison between MRI and other imaging modalities, these modalities were also analyzed. Sensitivity was defined as the number of lesions visible on MRI divided by the total number of ILC detected at pathology. We regarded morphology, dynamic curve analysis of contrast behavior, and quantitative dynamic analysis of contrast behavior as three different aspects of tumor appearance and these were thus analyzed separately. A principal distinction between mass-like and nonmass-like lesions was made in the analysis of morphology. Based on the BI-RADS lexicon [14], we defined architectural distortion, regional, segmental, ductal, multifocal, or diffuse enhancement, and multiple enhancing foci as descriptors of non-mass lesions. Nodular or focal enhancement, well-defined, round, irregular or spiculated masses, and dominant masses 
with small enhancing foci were defined as descriptors of mass-like lesions. Correlation between the findings on MRI and pathology was evaluated for relative tumor size (unifocal versus multifocal disease and single quadrant versus multicentric disease) and absolute tumor size. The impact on surgical management was derived from all changes implemented, based solely on MRI findings. The numbers of correct and incorrect changes were tabulated.

\section{Eligibility criteria}

All studies that presented a series of at least ten patients with histologic proof of pure ILC, with or without concurrent DCIS and/or LCIS, were considered eligible. A quality analysis of the study had to be possible, otherwise no abstracts were accepted. Patients with mixed carcinomas of ILC and IDC were excluded. Studies that presented data on both ILC and mixed carcinomas had to allow extraction of the relevant data for ILC only. Every study considered eligible according to these eligibility criteria was then evaluated for all the study endpoints. Specific eligibility criteria for the various considered endpoints are described below.

Detection: Studies had to be based on a pathology database and all subsequent patients with ILC who underwent a MRI had to be included. The total number of ILC confirmed at pathology had to be clearly stated as well as the number of lesions found with MRI.

Morphology: Studies describing the appearance of ILC visible on MRI were eligible. Separation between mass and non-mass-like lesions had to be possible.

Dynamic curve analysis of contrast behavior: Studies that described the enhancement versus time curve were eligible. However, as time to peak and shape of the final phase of the enhancement curve were our main endpoints, these had to be described.

Quantitative analysis of contrast behavior: Studies performing quantitative analysis of the contrastenhancement parameters were eligible.

Relative correlation with pathology: Studies presenting data on the unifocal versus multifocal correlation or single quadrant involvement versus multicentric involvement were eligible.

Absolute correlation with pathology: Studies comparing sizes measured on MRI with those measured at pathology and presenting a correlation coefficient or sufficient raw data to calculate such a value were eligible.

Detection of additional lesions: Any study describing additional lesions apart from the index lesion detected by MRI only with subsequent acquisition of histologic proof of malignancy was considered eligible. Lesions in the ipsilateral breast and the contralateral breast were evaluated separately.

Impact on surgical treatment: Studies mentioning all changes in surgical strategy based on MRI findings were eligible.

\section{Statistics}

The quality of all included studies was assessed using the QUADAS tool [15]. The latter is a list of 14 items created for quality assessment of studies to diagnostic accuracy. Although not all the included studies specifically evaluate diagnostic accuracy, this tool was judged to be the most appropriate available. Data of all the studies were collected according to the inclusion and exclusion criteria. When at least five studies presented the same type of data or at least 100 patients were included in a smaller series of studies with similar data, we considered meta-analysis and heterogeneity analysis was performed. Dichotomous data with a binomial distribution (e.g., sensitivity) were transformed to the log odds scale because this scale has a normal distribution and is a good approximation to the exact binomial distribution. A disadvantage of this transformation, however, is that the confidence intervals are a little wider and values in the middle of the distribution (e.g., sensitivity closer to $50 \%$ ) are more heavily weighted in meta-analysis than values close to the upper or lower level. Pearson's correlation coefficient was transformed to Fisher's $Z$ for the same reason [16].

We calculated Cochran's $Q$ coefficient and the $I^{2}$-statistic to assess heterogeneity. Cochran's $Q$ is a form of the $\chi^{2}$-test and provides information about the applicability of pooling the data. The $I^{2}$-statistic provides a quantitative measure of the amount of heterogeneity and has an upper limit of $100 \%$. Values of the $I^{2}$-statistic of 25,50 , and $75 \%$ can be interpreted as low, moderate, and high heterogeneity, respectively [17]. Meta-analysis of the data using a random effects model was performed when the $Q$-coefficient showed no significant heterogeneity $(p>0.05)$.

In cases where meta-analysis was feasible, the estimate and the $95 \% \mathrm{CL}$ are expressed. When 
meta-analysis was not feasible due to severe heterogeneity, only the range of values found in the different studies is mentioned. All calculations were performed using $\mathrm{R}$ version 2.3.1 (The R Project for Statistical Computing, www.r-project.org) and the meta package (G. Schwarzer, cran.r-project.org).

\section{Results}

Studies

We identified 21 separate studies that dealt with MRI and ILC [18-38]. We further identified four studies that did not deal specifically with ILC and MRI. However, they did present their data in such a fashion that relevant information for ILC only could be extracted for at least ten patients [39-42]. Four studies were casereports and were dropped from the cohort [20, 21, 29, 37]. The study by Bazzocchi et al. [18] was excluded because only eight patients underwent MRI. Leung et al. [27] and Newstead et al. [42] only published their findings in abstract form and were consequently excluded. Table 1 gives an overview of the included studies and their characteristics, including the QUADAS score.

The applied scan protocols in the included studies are diverse. In general, most studies presented herein used a 1.5-T MRI scanner, although some authors had at least some of their included patients scanned using 1.0 T machines $[33,34,40]$. Most protocols were based on $\mathrm{T} 1$ weighted images made with either a normal FLASH 3D sequence or a FLASH 3D sequence with fat-suppression [19, 20, 23, 24, 26, 31, 33-36, 38, 40, 41] or a RODEO sequence with water selective excitation $[25,30,32]$. A number of authors also used $\mathrm{T} 2$ weighted sequences $[22,23,31,38,40,41]$. Other differences in scan protocols involve the voxel sizes and temporal resolution. Some authors emphasize high spatial resolution [32, 39] while others prefer high temporal resolution [26] and yet again others performed both types of sequences in succession [30, 38]. Furthermore, single breast coils [26, 30, 32, 36, 41, 43] and double breast coils (all others) were used and sometimes compression was applied to the imaged breast $[31,36,39]$. In most reported studies the scanning protocols evolved over time and are thus not identical for all imaged patients.

\section{Lesion detection}

Eight studies provided sufficient data to calculate sensitivity of MRI for ILC [19, 23, 24, 26, 28, 33, 34, 40].
Sensitivity ranged from 83 to $100 \%$. Cochran's $Q$ was $6.48(p=0.49), I^{2}$ was $0 \%$, indicating homogeneous studies and hence data pooling could be performed. Mean sensitivity was $93.3 \%$ (95\% CI $88-96 \%$ ). Only the studies by Francis et al. [24] and Berg et al. [40] provided prospective data and are therefore able to show sensitivity in clinical practice. They showed a sensitivity of 95 and $97 \%$, respectively, and were statistically not different from the retrospective studies (two-sided $T$-test, $p=0.78$ ). Seven of these studies also provided data on mammography $[Q 31.79(p<0.001)$,

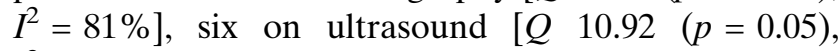
$\left.I^{2}=54 \%\right]$, and five on clinical examination $[Q 29.63$ $\left.(p<0.001), I^{2}=87 \%\right]$. Sensitivity of ultrasound could also be computed through meta-analysis and was $83 \%$ (95\% CI 71-91\%), although moderate heterogeneity was present. The provided data for mammography and clinical examination were too heterogeneous for metaanalysis and ranged from 34 to 91 and 28 to $94 \%$, respectively. Figure 1 shows the results of each independent study and the overall results.

\section{Morphology}

Seven studies described lesion morphology on static MRI images [23, 30, 32, 33, 36, 38, 41]. However, Kim et al. [41] studied morphologic appearances of masses only and therefore did not include non-mass-like lesions. Information provided by their study is therefore only used to evaluate the appearance of masses and not for the principal distinction between mass and non-mass lesions. The terminology used in the literature to describe the lesions is highly variable. Only Yeh et al. [38] consistently used the terminology of the BI-RADS lexicon [14]. The six eligible studies that presented data on morphologic appearance described a total of $133 \mathrm{tu}-$ mors. However, results are highly variable. The incidence of a mass-like lesion ranged from 31 to $95 \%$ $\left[\begin{array}{ll}Q & 16.44(p<0.01), I^{2}=70 \%\end{array}\right]$. Table 2 shows the appearance of ILC on MRI for all individual studies.

Fabre Demard et al. [23] did not specify the lesions beyond the description "mass-like." Other authors used many different terms to further describe lesions. In the study presented by Rodenko et al. [32], five predefined shapes were used, but they described all 19 mass-like lesions as spicular enhancing masses. In the other studies most lesions are described as spiculated masses as well. Schelfout et al. [33] recognized a dominant mass with multiple enhancing foci in eight cases and Yeh et al. [38] described even a round focal mass. In the 12 mass-like cases described by Kim et al. [41], 10 had an irregular shape and 8 were spiculated. Therefore, among the 76 masses, a total of 65 tumors 
Table 1 Characteristics of the included studies

\begin{tabular}{|c|c|c|c|c|c|c|c|c|c|c|c|c|}
\hline Authors & $\begin{array}{l}\text { Pub. } \\
\text { Year }^{a}\end{array}$ & $\begin{array}{l}\text { Study } \\
\text { type }^{\mathrm{b}}\end{array}$ & $\mathrm{N}^{\mathrm{c}}$ & $\begin{array}{l}\text { Age } \\
\text { mean }^{\text {d }}\end{array}$ & $\begin{array}{l}\text { Age } \\
\text { min. }\end{array}$ & $\begin{array}{l}\text { Age } \\
\text { max. }\end{array}$ & Field $^{g}$ & $\begin{array}{l}\text { Scan } \\
\text { seq. }\end{array}$ & $\begin{array}{l}\text { Uni/ } \\
\text { bilat }^{\mathrm{i}}\end{array}$ & Compression $^{\mathrm{j}}$ & $\begin{array}{l}\text { Mean } \\
\text { size }^{k}\end{array}$ & $\begin{array}{l}\text { QUADAS } \\
\text { score }^{1}\end{array}$ \\
\hline $\begin{array}{l}\text { Rodenko et al. } \\
\text { [32] }\end{array}$ & 1996 & 1 & 20 & 60 & 38 & 84 & 2 & 1 & 1 & 0 & $\mathrm{X}$ & 11 \\
\hline Sittek et al. [34] & 1998 & 1 & 23 & $X$ & $X$ & $\mathrm{X}$ & 1 & 2 & 2 & 0 & $X$ & 11 \\
\hline $\begin{array}{l}\text { Weinstein et al. } \\
\text { [36] }\end{array}$ & 2001 & 1 & 17 & 53 & 32 & 69 & 2 & 2 & 1 & 1 & 1,7 & 12 \\
\hline Kim et al. [41] & 2001 & 1 & 12 & $54^{\mathrm{m}}$ & $24^{\mathrm{m}}$ & $88^{\mathrm{m}}$ & 2 & 2 & 1 & 0 & $2,1^{\mathrm{m}}$ & 12 \\
\hline Trecate et al. [35] & 2001 & 1 & 28 & $\mathrm{X}$ & 32 & 81 & 2 & 2 & 2 & 0 & $\mathrm{X}$ & 9 \\
\hline Francis et al. [24] & 2001 & 2 & 22 & $X$ & $X$ & $\mathrm{X}$ & 2 & 2 & 2 & 0 & 3,7 & 12 \\
\hline Qayyum et al. [30] & 2002 & 1 & 13 & 55 & 46 & 84 & 2 & 1 & 1 & 0 & $\mathrm{X}$ & 11 \\
\hline Munot et al. [28] & 2002 & 1 & 20 & 61 & 39 & 78 & 2 & 3 & 2 & 0 & $\mathrm{X}$ & 11 \\
\hline Yeh et al. [38] & 2003 & 1 & 19 & 59 & 42 & 79 & 2 & 2 & 2 & 0 & 4,1 & 11 \\
\hline $\begin{array}{l}\text { Kneeshaw et al. } \\
\text { [26] }\end{array}$ & 2003 & 1 & 21 & 57 & 43 & 72 & 2 & 2 & 1 & 0 & $X$ & 11 \\
\hline Quan et al. [31] & 2003 & 1 & 62 & 53 & $X$ & $\mathrm{X}$ & 2 & 2 & 3 & 1 & $X$ & 10 \\
\hline $\begin{array}{l}\text { Bedrosian et al. } \\
\text { [39] }\end{array}$ & 2003 & 1 & 24 & $53^{\mathrm{m}}$ & $X$ & $\mathrm{X}$ & 2 & 0 & 0 & 1 & $\mathrm{X}$ & 10 \\
\hline $\begin{array}{l}\text { Schelfout et al. } \\
\text { [33] }\end{array}$ & 2004 & 1 & 26 & 57 & 41 & 74 & 3 & 2 & 2 & 0 & $X$ & 11 \\
\hline $\begin{array}{l}\text { Diekmann et al. } \\
\text { [22] }\end{array}$ & 2004 & 1 & 17 & $\mathrm{X}$ & $\mathrm{X}$ & $\mathrm{X}$ & 0 & 0 & 0 & 0 & $\mathrm{X}$ & 10 \\
\hline Boetes et al. [19] & 2004 & 1 & 34 & 55 & 35 & 78 & 2 & 2 & 2 & 0 & 4,9 & 10 \\
\hline Berg et al. [40] & 2004 & 2 & 29 & $X$ & $X$ & $\mathrm{X}$ & 3 & 2 & 2 & 0 & $X$ & 13 \\
\hline Kepple et al. [25] & 2005 & 1 & 29 & 62 & 51 & 67 & 2 & 1 & 3 & 0 & $X$ & 9 \\
\hline $\begin{array}{l}\text { Fabre Demard } \\
\text { et al. [23] }\end{array}$ & 2005 & 1 & 34 & $\mathrm{X}$ & $X$ & $\mathrm{X}$ & 2 & 2 & 2 & 0 & $X$ & 11 \\
\hline
\end{tabular}

a Year of publication of the original article

b 1 indicates retrospective cohort study, 2 indicates prospective cohort study

c Number of patients included

${ }^{\mathrm{d}}$ Mean age of all included patients, $\mathrm{X}$ denotes not mentioned

e Age of respective youngest patient included in the study

f Age of respective eldest patient included in the study

g Strength of magnetic field-0 denotes unknown, 1 denotes $1 \mathrm{~T}, 2$ denotes $1.5 \mathrm{~T}, 3$ denotes both $1 \mathrm{~T}$ and $1.5 \mathrm{~T}$

h Type of scan sequence used-0 denotes unknown, 1 denotes RODEO, 2 denotes FLASH 3D, 3 denotes other

${ }^{\mathrm{i}}$ Unilateral or bilateral imaging of the breast -0 denotes unknown, 1 denotes unilateral, 2 denotes bilateral, 3 denotes both unilateral and bilateral depending on the patient

${ }^{\mathrm{j}}$ Compression applied to the breast -0 denotes no, 1 denotes yes

${ }^{\mathrm{k}}$ Mean size of the lesions in centimeters, $\mathrm{X}$ denotes not mentioned

${ }^{1}$ Number of items valid on QUADAS scorings list

${ }^{\mathrm{m}}$ Valid for whole study population only, not for subpopulation of patients with ILC

were described as an irregular or spiculated mass. This appears to be the most common type of mass-like presentation in ILC.

\section{Kinetics}

Only two studies reported on the dynamic curve appearance of ILC $[34,35]$. The most apparent similarity between findings was that maximum enhancement is often delayed and wash-out is present in only a minority of lesions. Sittek et al. [34] reported that maximum enhancement was not reached before $2 \mathrm{~min}$ after contrast administration. Trecate et al. [35] noted that a classic pattern of rapid signal increase was only present in 4 of 12 pure ILC, whereas a delayed pattern was observed in the other 8 cases.

Two other studies reported on quantitative contrast behavior analysis in ILC [30, 38]. Qayyum et al. [30] reported on a parameter called $\mathrm{K} 21$, analogue to the $K^{\text {trans }}$ parameter as described by Tofts et al. [44]. Yeh et al. [38] evaluated the extraction flow product (EFP), which is a similar analogue but respects the possibility that contrast leakage from the vessels is limited by flow instead of being limited by the permeability surface area product. Both studies did not, however, include sufficient patients to produce meaningful results, other than a high variability in the values of these parameters and the presence in some tumors of enhancement very 


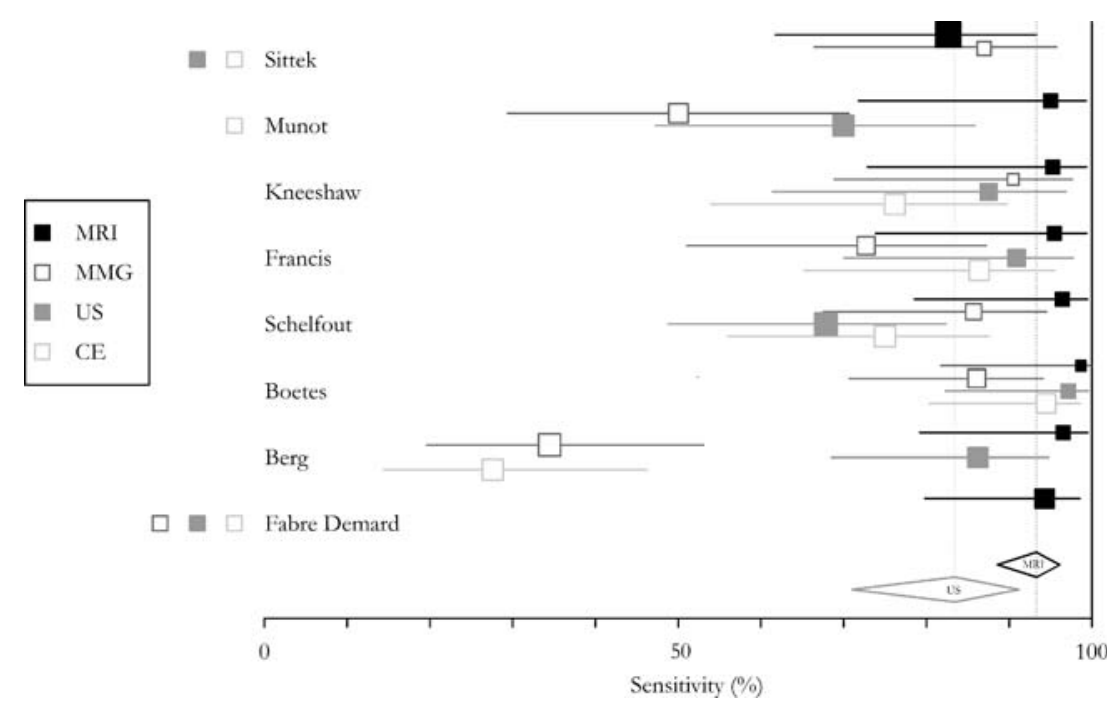

Fig. 1 Forestplot of the sensitivity of the respective modalities for $I L C$ (MMG mammography, $U S$ ultrasound, $C E$ clinical examination), the horizontal lines represent $95 \%$ confidence intervals. Modalities presented on the right of the authors name have not been tested in the appropriate study. The diamonds at the bottom represent the pooled estimates and their $95 \%$ confidence intervals for $M R I$ and $U S$, respectively. Because mammography and clinical examination were too heterogeneous for meta-analysis no pooled estimate is presented for these modalities
Table 2 Morphologic appearance of ILC on MRI

Numbers between parenthesis represent percentages

\begin{tabular}{llrr}
\hline Authors & Number of tumors & Non-mass-like & Mass-like \\
\hline Rodenko et al. [32] & 20 & $1(5)$ & $19(95)$ \\
Weinstein et al. [36] & 18 & $8(44)$ & $10(56)$ \\
Qayyum et al. [30] & 13 & $9(69)$ & $4(31)$ \\
Yeh et al. [38] & 20 & $11(55)$ & $9(45)$ \\
Schelfout et al. [33] & 27 & $6(22)$ & $21(78)$ \\
Fabre Demard et al. [23] & 35 & $11(31)$ & $24(69)$ \\
\hline
\end{tabular}

much like enhancement in normal breast tissue. It was noted that $\mathrm{K} 21$ values appeared to be an order of magnitude less in ILC than in IDC lesions.

\section{Correlation}

Several authors evaluated correlation of the MRI findings with pathology [19, 24-26, 28, 32, 33, 40]. Three studies compared unifocality and multifocality between MRI and pathology [26, 32, 33] (Table 3). Overall 5 of 67 cases (7\%) were regarded as multifocal, whereas they appeared unifocal at pathology and, vice versa, 2 cases $(3 \%)$ in one study appeared unifocal at MRI, but were multifocal according to pathology.

Overestimation of multifocality based on mammography in 63 patients from these studies occurred in 2 patients $(3 \%)$, whereas underestimation occurred 25 times $(40 \%)$ and the lesion was not visible on mammography in another 4 patients $(6 \%)$.

Two of these studies further analyzed single quadrant versus multicentric involvement of the affected breast [32, 33] (Table 4). In the study by Rodenko

Table 3 Relative correlation of unifocality versus multifocality for MRI versus pathology

\begin{tabular}{llclllll}
\hline Authors & Number of patients & UF MRI & UF PATH & MF MRI & MF PATH & Overestimated $^{\text {a }}$ & Underestimated $^{\text {b }}$ \\
\hline Rodenko et al. [32] & 20 & 9 & 11 & 11 & 9 & 2 & 1 \\
Kneeshaw et al. [26] & 21 & 9 & 10 & 12 & 11 & 1 & 0 \\
Schelfout et al. [33] & 26 & 14 & 17 & 12 & 10 & 2 & 1 \\
Total & 67 & & & & & 5 & 2 \\
\hline
\end{tabular}

$U F$ unifocal, $M F$ multifocal, $P A T H$ pathology

a Disease was classified as multifocal on MRI, but was unifocal on pathology

b Disease was classified as unifocal on MRI, but was multifocal on pathology 
et al. [32], two cases of single quadrant disease were erroneously classified as multicentric on MRI.

Mammography in 42 of these patients resulted in overestimation of disease extent in 1 patient and underestimation in 15. Again, no lesion was visible in four patients.

Berg et al. [40] further showed a series of 12 patients that underwent MRI. Correct size estimation was performed in seven patients. In one patient an additional focus was missed and in four patients overestimation occurred due to foci of LCIS.

Absolute correlation of MRI and pathologic size measurement was performed by six authors $[19,24-26$, 28, 32]. Rodenko et al. [32] found a Kappa coefficient of 0.77, which represents substantial agreement. The other authors presented Pearson's correlation coefficients ranging from 0.81 to $0.97\left[\begin{array}{ll}Q & 10.90\end{array}\right.$ $\left.(p=0.03), I^{2}=63 \%\right]$. Correlation coefficients for other modalities were substantially more variable. Presented correlation coefficients in Table 5 are optimized by excluding cases where no abnormalities were seen from the calculations.

Boetes et al. [19] applied a correctness measure of $1.0 \mathrm{~cm}$ to their data and found that MRI underestimated disease extent in 5 of 36 tumors and overestimated extent in 4 cases by more than $1.0 \mathrm{~cm}$. The data provided by Francis et al. [24] allow a similar calculation. Underestimation occurred in 6 of 22 cases and overestimation occurred in 1.

\section{Additional lesions}

Five studies focused on the detection of concurrent additional lesions in the affected breast apart from the index lesion only visible by MRI [22, 23, 31, 33, 36]. In 44 of 146 patients, additional malignant lesions were found $\left[\begin{array}{lll}Q & 7.20 \quad(p=0.13), I^{2}=44 \%\end{array}\right]$. Additional malignant findings only visible on MRI were present in $32 \%$ of cases $(95 \%$ CI $22-44 \%)$. The results of the individual studies are presented in Table 6 .
Eight studies, presented in Table 7, reported on findings in the contralateral breast $[19,22-25,28,31,40]$. In 12 of 206 patients, unexpected contralateral cancer was discovered exclusively by MRI $[Q 2.28(p=0.94)$, $\left.I^{2}=0 \%\right]$. Cases where contralateral cancer was also visible on mammography and/or ultrasound are excluded. Contralateral carcinoma only visible by MRI was present in $7 \%$ of patients ( $95 \%$ CI $4-12 \%$ ).

\section{Effect on surgical treatment}

Six studies explicitly stated the effect of MRI on the surgical treatment of their patients $[23,26,28,31$, 32, 39]. In 160 patients with ILC, a total of 44 changes in surgical management occurred $[Q 7.90$ $\left.(p=0.16), I^{2}=37 \%\right]$. Overall, MRI changed the surgical management in $28.3 \%$ of cases $(95 \%$ CI 20-39\%). In 24 cases BCT was changed to mastectomy. In nine cases a wider local excision was performed. In the remaining 11 cases the type of change was not further described. Forty-one of 44 changes in surgical management were retrospectively judged necessary based on pathologic findings $\left[\begin{array}{ll}Q & 1.24\end{array}\right.$ $\left.(p=0.94), I^{2}=0 \%\right]$. Therefore, $88 \%$ of all changes were correct $(95 \%$ CI $75-95 \%)$. In three cases the change in management was retrospectively judged unnecessary based on pathology. The data of the individual studies are presented in Table 8 .

Rodenko et al. [32] and Kneeshaw et al. [26] both reported one further unnecessary mastectomy based on MRI outcomes. However, these mastectomies would also have been performed based on the mammography findings and are therefore not only due to the MRI. Berg et al. [40] also reported that findings on MRI in 12 patients with ILC would have resulted in two unnecessary mastectomies. However, mastectomies were also indicated according to the ultrasound report. Nonetheless they based their treatment on the mammograms only and therefore these mastectomies were not performed.

Table 4 Relative correlation of single quadrant versus multicentric involvement for MRI versus pathology

\begin{tabular}{llrlrlll}
\hline Authors & $\begin{array}{l}\text { Number } \\
\text { of patients }\end{array}$ & SQ MRI & SQ PATH & MC MRI & MC PATH & Overestimated $^{\text {a }}$ & Underestimated $^{\text {b }}$ \\
\hline Rodenko et al. [32] & 20 & 9 & 11 & 11 & 9 & 2 & 0 \\
Schelfout et al. [33] & 26 & 21 & 21 & 5 & 5 & 0 & 0 \\
Total & 46 & & & & & 2 & 0 \\
\hline
\end{tabular}

$S Q$ single quadrant, $M C$ multicentric, $P A T H$ pathology

${ }^{a}$ Multicentric involvement was seen on MRI, but involvement of only one quadrant was shown on pathology

b Involvement of only one quadrant was seen on MRI, but on pathology multicentric involvement was shown 
Table 5 Correlation of tumor size measured by various modalities compared to pathology

\begin{tabular}{|c|c|c|c|c|c|c|c|c|c|c|c|c|}
\hline \multirow[t]{2}{*}{ Authors } & \multicolumn{3}{|c|}{ MRI } & \multicolumn{3}{|c|}{ MMG } & \multicolumn{3}{|l|}{ US } & \multicolumn{3}{|c|}{$\mathrm{CE}$} \\
\hline & $N$ & PCC & $\mathrm{K}$ & $N$ & $\mathrm{PCC}$ & $K$ & $N$ & PCC & $K$ & $N$ & PCC & $K$ \\
\hline Rodenko et al. [32] & 20 & & 0.773 & 15 & & -0.081 & & & & & & \\
\hline Munot et al. [28] & 20 & 0.97 & & 10 & 0.66 & & 14 & 0.67 & & & & \\
\hline Kneeshaw et al. [26] & 21 & 0.86 & & 21 & $0.93^{\mathrm{a}}$ & & 21 & $0.93^{\mathrm{a}}$ & & 21 & 0.47 & \\
\hline Francis et al. [24] & 22 & 0.87 & & 16 & 0.79 & & 20 & 0.56 & & 19 & 0.89 & \\
\hline Boetes et al. [19] & 36 & 0.81 & & 36 & 0.34 & & 36 & 0.24 & & & & \\
\hline Kepple et al. [25] & 33 & 0.88 & & & & & 9 & 0.71 & & & & \\
\hline
\end{tabular}

$M M G$ mammography, $U S$ ultrasound, $C E$ clinical examination, $N$ number of lesions visible on the appropriate modality, $P C C$ Pearson's correlation coefficient, $K$ Kappa value

${ }^{a}$ Kneeshaw et al. did not provide a correlation coefficient for either MMG or US, but only one for the combined modalities

Table 6 Additional malignant findings in the ipsilateral breast by MRI

\begin{tabular}{lcc}
\hline Authors & $\begin{array}{l}\text { Number } \\
\text { of patients }\end{array}$ & $\begin{array}{l}\text { Number of } \\
\text { additional findings }\end{array}$ \\
\hline Weinstein et al. [36] & 18 & 7 \\
Quan et al. [31] & 51 & 11 \\
Schelfout et al. [33] & 26 & 9 \\
Diekmann et al. [22] & 17 & 9 \\
Fabre Demard et al. [23] & 34 & 8 \\
Total & 146 & 44 \\
Meta-analysis (\%) & 100 & 32 \\
\hline
\end{tabular}

Table 7 Additional findings in the contralateral breast by MRI

\begin{tabular}{lcc}
\hline Authors & $\begin{array}{l}\text { Number of } \\
\text { patients }\end{array}$ & $\begin{array}{l}\text { Number of } \\
\text { contralateral findings }\end{array}$ \\
\hline Francis et al. [24] & 22 & 0 \\
Munot et al. [28] & 20 & 2 \\
Quan et al. [31] & 53 & 5 \\
Diekmann et al. [22] & 17 & 1 \\
Boetes et al. [19] & 34 & 2 \\
Berg et al. [40] & 15 & 0 \\
Kepple et al. [25] & 14 & 0 \\
Fabre Demard et al. [23] & 34 & 2 \\
Total & 206 & 12 \\
Meta-analysis (\%) & 100 & 7 \\
\hline
\end{tabular}

\section{Discussion}

Studies and quality analysis

We included 18 studies, but the highest number of studies that could be used to answer a specific endpoint was 8 (sensitivity and contralateral findings). Strong evidence is therefore lacking and this review is thus a clear call for more substantial research in this area. The overall study quality of all studies is, according to the QUADAS score, reasonably high (lowest score $=9 / 14$ ). However, this tool does not include the study size in the analysis, which was generally low. The tool places a strong emphasis on the relation of the test to the reference standard (typical for observational studies). In all studies, the reference standard was pathology and therefore always acceptable as gold standard. However, the test results (in this case the MRI reports), were never shielded from the pathologist who performed the pathologic evaluation. In studies that were performed to evaluate the visual characteristics of ILC on MRI a thorough description of the pathological examination was, deservedly so, not included [23, 30, 32, 33, 36, 38, 41]. These studies thus scored a little lower. There are some other drawbacks that must be considered and that are not included in the QUADAS score. Firstly, all but 2 of the included 18 studies were retrospective in nature, and secondly, the applied MRI protocols were largely heterogeneous (see Table 1). However, the presented data were extracted from studies that made use of the various standards in MRI of the breast of the last decade and therefore give a reasonable overview of the overall capability of MRI in ILC imaging in this period.

\section{Sensitivity}

The sensitivity of physical examination and conventional imaging for ILC of the breast is not optimal. The sensitivity of physical examination for ILC ranges between 65 and 98\% [10, 45-47], with usually over $50 \%$ of patients presenting with palpable abnormalities.

The sensitivity of mammography for ILC (BIRADS 3 or higher) ranges between 81 and $92 \%$ in literature [10, 45-51]. In a recent study that evaluated intra- and interobserver variability, sensitivity even ranged from 88 to $98 \%$ [52], which could be regarded as sufficient. However, ILC often do not appear as a malignant lesion on mammography; approximately $30 \%$ is classified as equivocal and sensitivity is then approximately $57-59 \%$ [51]. 
Table 8 Changes in surgical management based solely on MRI findings

\begin{tabular}{|c|c|c|c|c|c|c|c|c|}
\hline Authors & $\begin{array}{l}\text { Number } \\
\text { of } \\
\text { patients }\end{array}$ & $\begin{array}{l}\text { Number } \\
\text { of } \\
\text { changes }\end{array}$ & $\begin{array}{l}\text { Correct } \\
\text { changes }\end{array}$ & $\begin{array}{l}\text { Incorrect } \\
\text { changes }\end{array}$ & $\begin{array}{l}\text { Correct } \\
\text { wider } \\
\text { excision }\end{array}$ & $\begin{array}{l}\text { Incorrect } \\
\text { wider } \\
\text { excision }\end{array}$ & $\begin{array}{l}\text { Correct } \\
\text { mastectomy }\end{array}$ & $\begin{array}{l}\text { Incorrect } \\
\text { mastectomy }\end{array}$ \\
\hline Rodenko et al. [32] & 20 & 8 & 7 & 1 & & & 7 & 1 \\
\hline Munot et al. [28] & 20 & 3 & 3 & & & & 3 & \\
\hline Kneeshaw et al. [26] & 21 & 5 & 5 & & 1 & & 4 & \\
\hline Quan et al. [31] & 51 & 11 & 11 & & 5 & & 6 & \\
\hline Bedrosian et al. [39] & 24 & 11 & 9 & 2 & NA & NA & NA & NA \\
\hline Fabre Demard et al. [23] & 24 & 6 & 6 & & 3 & & 3 & \\
\hline Total & 160 & 44 & 41 & 3 & 9 & & 23 & 1 \\
\hline Number of changes $(\%)$ & 100 & 28.3 & & & & & & \\
\hline Correct changes $(\%)$ & & 100 & 88 & & & & & \\
\hline
\end{tabular}

Number of changes and correct changes show the result of meta-analyses

$N A$ not available

The overall sensitivity of mammography in the current analysis appears lower than findings in the literature on mammography in ILC. However, equivocal findings may have been classified as undetected lesions in some studies resulting in the overall lower results. Nevertheless, the sensitivities of only $34 \%$ found by Berg et al. [40], and 50\% found by Munot et al. [28] are on the lower end of the spectrum. Munot et al. [28] did not state which views constituted their mammograms, while Berg et al. [40] made craniocaudal, mediolateral and spot-compression views on a standard mammography machine, which we regard as common practice. A possible explanation for the poor results in the study by Berg et al. [40] may be that they defined an ILC as a focus of tumor, thereby allowing more tumors to be present in one breast, whereas other authors defined this as multifocal or multicentric tumors and thus as detected when at least one lesion was visible on mammography.

In literature, the reported sensitivity of ultrasound for ILC ranges between 68 and 98\% [47, 53-58]. As this range is comparable to the range found in the present evaluation, we are of the opinion that an overall sensitivity of $83 \%$ is accurate. However, application of newer high-frequency ultrasound transducers may improve sensitivity. Initial series using $7.5 \mathrm{MHz}$ transducers show sensitivities of $68 \%$ [47] and $78 \%$ [56], whereas series that used $10-13 \mathrm{MHz}$ transducers report sensitivities up to $98 \%$ [57, 59].

Contrast-enhanced MRI is nowadays widely accepted as the most sensitive modality for detection of malignancy of the breast. Early reports on overall sensitivity of MRI for breast lesions range from 93 to $100 \%$ [13, 60-63]. Thus, the sensitivity of MRI found for ILC in the studies presented herein and the overall sensitivity of $93.3 \%$ calculated from these studies are not different from those known for malignancy in the breast in general. The relatively low heterogeneity of all studies describing lesion detection as well as detection of additional lesions in the ipsi- and contralateral breast show that the applied MRI technique only has a minor impact on the ability of MRI to detect lesions.

The overall sensitivity could even be increased to $96 \%$ (95\% CI $92-98 \%$ ) if an early study is excluded from the analysis [34]. This study reported a sensitivity for ILC of only $83 \%$, a discrepancy that may well be explained by the fact that the slice thickness in this study was $4.2 \mathrm{~mm}$, thicker than in any of the other presented studies, which could have had a negative impact on sensitivity. Moreover, 15 of 23 patients in their series were scanned with a FLASH 3D sequence with TR 8.4/TE 3.0, resulting in image acquisition with a phase-shift of water and fat, which might have further decreased their sensitivity, although this was not apparent from their data.

It must be taken into account that the acquired sensitivity in all studies was achieved in cases where prior knowledge of the existence of ILC was present. Mostly because of the retrospective nature of the presented studies, but also because the two prospective studies both included their patients on the basis of histological proof of invasive (lobular) carcinoma by core biopsy. It is therefore not possible to formulate conclusions on the sensitivity of MRI for ILC prior to biopsy. In a large multicenter trial by Bluemke et al. [64] overall sensitivity for invasive cancer prior to biopsy was $91 \%$, thus it might be expected that sensitivity for ILC prior to biopsy is also slightly lower. However, in most cases the indication for MRI is 
assessment of disease extent because of inconclusive findings at mammography or ultrasound. In conclusion, the sensitivity of MRI for ILC is higher than that achieved by any other modality, in direct comparison and validated by literature, and is equal to the overall sensitivity of MRI for malignant lesions of the breast. Only modern ultrasound examinations seem to have the ability to approach the performance of MRI in the detection of ILC [57].

\section{Morphology}

The morphologic appearance of ILC on MRI ranged from $69 \%$ non-mass-like lesions to $95 \%$ mass-like lesions, thereby raising questions concerning the amount of heterogeneity in the description of morphology of lesions by radiologists. In fact, the general agreement on the description of lesion type according to the BI-RADS lexicon is only moderate $[14,65]$. In the current analysis, this is even further complicated because most authors did not specifically use the BI-RADS lexicon. Additionally, differences in scan techniques may have further affected the appearance of the lesion. However, in keeping with the above, the classification of lesion type is also highly variable on mammography, where the incidence of mass lesions ranges from 32 to $78 \%$ [10, 45, 46, 48, $50,51,55]$.

The vast majority of the mass-like lesions described on MRI are irregular or spicular lesions. The eight patients with a dominant mass surrounded by multiple enhancing foci, as described by Schelfout et al. [33], may present noncontiguous foci of disease without visible spiculae due to the absence of desmoplastic reaction, which is a well-known histopathological presentation [8]. In all series only one round mass was described [38], suggesting this to be a very rare presentation for ILC. This is consistent with findings in mammography by Le Gal et al. [10], who described a round mass in only $2 \%$ of all patients where a mass was present (4/174) while the remainder was either classified as a spicular mass (54\%) or poorly defined mass (44\%).

Mammographic findings would therefore appear to correlate well with MRI findings. However, only one study allows direct comparison [33]: of all lesions visible in this study on both mammography and MRI, 78\% $(18 / 23)$ were classified as mass-like by MRI, while only $48 \%(11 / 23)$ were classified as mass-like by mammography. Six masses on MRI were visible as architectural distortion on mammography and two as asymmetric density. In one case a lesion described as spicular mass on mammography was visible on MRI as multiple enhancing foci with interconnecting enhancing strands.

Non-mass-like ILC in mammography are typically described as architectural distortion or asymmetric density. In some cases microcalcifications are present, although these are often related to concurrent surrounding DCIS, sclerosing adenosis or fibrotic changes and might thus not be related to the presence of ILC $[45,51,55]$. The descriptors currently used for nonmass-like lesions on MRI are diverse and include various types of abnormal enhancement, such as regional, ductal, segmental, and diffuse enhancement. According to Qayyum et al. [30] the morphologic description of ILC on MRI has a good correlation to histopathologic findings. The non-mass-like presentation might specifically occur in cases where ILC grow in the classic pattern with cells arranged in a linear fashion along the ductuli.

It may thus be concluded that the appearance of most ILC on MRI and mammography is similar: most ILC are mass-lesions that have clear malignant properties. However, the more diffuse growing tumors are characterized by areas of unexpected enhancement and are more difficult to recognize. In a number of cases where no clear mass is visible on mammography, a mass-like lesion may be found on MRI [33].

\section{Kinetics}

The relatively late contrast enhancement of ILC apparent in all studies presented here and mirrored by the relatively low values of K21 and EFP in the studies by Qayyum et al. [30] and Yeh et al. [38] must be taken into account when evaluating ILC. Standard subtraction images, generated from the pre-contrast and the first or second post-contrast acquisitions may be inconclusive as maximum enhancement is not achieved at this point in time and the lesion is thus not yet clearly visible. In fact, false-negative MRI in cases of ILC is usually contributed to inadequate enhancement of the tumor $[26,35,66]$. The diffuse and often slow tumor growth, not requiring extensive neovascularization, may partly cause this difficult visualization $[1,67,68]$. This is also clear from the relatively lower amount of vascular endothelial growth factor found in tumors with a lobular histology, which might also indicate a different signaling pathway in the formation of neovascular vessels in ILC, resulting in more mature and thus less leaky capillaries [69], with consequently diminished or absent contrast enhancement. 


\section{Correlation}

In the herein presented studies overestimation of lesion extent by mammography is rare, yet underestimation is more rule than exception. This is also confirmed by studies that specifically deal with mammography in cases of ILC. Yeatman et al. [5] showed that mammography underestimated ILC by a mean of $12 \mathrm{~mm}$. Uchiyama et al. [51] reported $56 \%$ of all visible ILC on mammography to be underestimated and Veltman et al. [52] showed $35-37 \%$ of all ILC to be mammographically understaged.

Ultrasound also tends to underestimate tumor size in the studies presented here. This finding is underlined by Tresserra et al. [70] and more recently by Watermann et al. [71], who documented a structural underestimation of $5.4 \pm 12.2 \mathrm{~mm}$ in cases of ILC versus $1.4 \pm 12.0 \mathrm{~mm}$ for cases of IDC. This might be partly due to the observation that US tends to underestimate larger tumors more than smaller tumors and low grade tumors more than high grade [70], consistent with the finding that ILC usually presents with slightly larger and less aggressive tumors [1, 5, 67, 72]. The current analysis shows that there is good correlation of tumor size measured on MRI compared to pathology. The various studies presented only moderately heterogeneous results.

In most cases MRI outperforms mammography and ultrasound in the assessment of disease extent. Most tumors are correctly classified as uni- or multifocal and multicentric disease is only seldom overestimated [19, 32].

\section{Additional lesions and effect on surgical treatment}

Especially important in this analysis is the detection of additional lesions apart from the index lesion in patients with ILC. The co-existence of other invasive malignant lesions apart from the index lesion in the ipsilateral breast in $32 \%$ of patients only visualized by MRI is high. Moreover, the detection of contralateral cancer in another $7 \%$ of patients by MRI only, seems to make MRI indispensable. These findings are confirmed by the rate of change in treatment of the ipsilateral breast based on MRI. The fact that change in treatment was considered correct, as verified by pathologic findings in the specimen, in $88 \%$ of cases shows that ILC is often more extensive than appreciated on conventional imaging.

However, various authors have shown that there is no significant difference in disease free survival (DFS) or overall survival (OS) after BCT or mastectomy in patients with breast cancer. Although some authors report more local recurrence in patients with ILC after BCT [2, 73], most authors showed that there is no difference in DFS or OS after BCT in ILC versus IDC $[74,75]$. On the other hand, Yeatman et al. [5] reported a higher rate of conversion from lumpectomy to mastectomy in ILC compared to IDC (17.5\% versus $6.9 \%)$. More recently, Molland et al. [68] reported similar findings (37.2\% versus $22.4 \%)$. Hussien et al. [2] even reported failure of BCT in patients with ILC in $63 \%$ $(34 / 54)$ of patients, resulting in conversion to mastectomy in $76 \%$ of failures (26/34). However, a very recent study by Morrow et al. [76] showed that BCT did not fail more often in patients with ILC when corrected for age and tumor size, although they still observed a trend of more excisions in patients with ILC [OR $1.58(0.89-2.79), p=0.12]$.

To date, there is no evidence suggesting increase in survival for patients with ILC due to the performance of MRI. What is then the added value of MRI? The rate of recurrence 10 years after BCT followed by radiotherapy is between 7 and $18 \%$ and is not significantly different from the rate of recurrence in case of IDC $[77,78]$. However, in view of the MRI findings (additional malignant lesions in $32 \%$ of patients), we can only conclude that in a large number of patients with ILC, surgery is not curative but merely debulking. As recurrence rates are fortunately much lower, we must assume that curative treatment is to be expected from adjuvant therapy. Unfortunately, because there is no possibility to determine which additional findings will respond to adjuvant therapy, the detection of additional lesions on MRI currently still requires a change of treatment when malignancy has been proven by core biopsy. This may further reduce the rate of recurrence in patients with ILC and may even improve survival. However, this requires confirmation in future studies.

\section{Conclusion}

Magnetic resonance imaging has a high sensitivity for ILC, not achieved by other imaging modalities. Therefore MRI is helpful in cases where conventional imaging is inconclusive. Morphology is often mass-like and a typical ILC presents as an irregular or spiculated mass. However, asymmetric enhancement that can be ductal, segmental, regional, or diffuse in nature may be the only sign of tumor. MRI measures disease extent with a high reliability. Although underestimation and overestimation of lesion size by MRI still occurs, it is more accurate than size determination by other modalities, indicating often more extensive tumor burden than expected. 
The underestimation by other imaging modalities results in more failure of $\mathrm{BCT}$, more re-excisions and more conversion to mastectomy in series where MRI is not used. MRI has an effect on surgical management in that when used to assess disease extent, surgical management was changed in $28.3 \%$ of which $88 \%$ were judged necessary based on pathology. Larger series of patients are required to confirm the findings of this review; especially evaluation of tumor morphology and dynamic profile seems feasible.

\section{References}

1. Arpino G, Bardou VJ, Clark GM, Elledge RM (2004) Infiltrating lobular carcinoma of the breast: tumor characteristics and clinical outcome. Breast Cancer Res 6(3):R149R156

2. Hussien M, Lioe TF, Finnegan J, Spence RA (2003) Surgical treatment for invasive lobular carcinoma of the breast. Breast 12(1):23-35

3. Li CI, Anderson BO, Daling JR, Moe RE (2003) Trends in incidence rates of invasive lobular and ductal breast carcinoma. JAMA 289(11):1421-1424

4. Peiro G, Bornstein BA, Connolly JL, Gelman R, Hetelekidis S, Nixon AJ, Recht A, Silver B, Harris JR, Schnitt SJ (2000) The influence of infiltrating lobular carcinoma on the outcome of patients treated with breast-conserving surgery and radiation therapy. Breast Cancer Res Treat 59(1):49-54

5. Yeatman TJ, Cantor AB, Smith TJ, Smith SK, Reintgen DS, Miller MS, Ku NN, Baekey PA, Cox CE (1995) Tumor biology of infiltrating lobular carcinoma. Implications for management. Ann Surg 222(4):549-559

6. Li CI, Daling JR, Malone KE, Bernstein L, Marchbanks PA, Liff JM, Strom BL, Simon MS, Press MF, McDonald JA, Ursin G, Burkman RT, Deapen D, Spirtas R (2006) Relationship between established breast cancer risk factors and risk of seven different histologic types of invasive breast cancer. Cancer Epidemiol Biomarkers Prev 15(5):946-954

7. Li CI, Uribe DJ, Daling JR (2005) Clinical characteristics of different histologic types of breast cancer. $\mathrm{Br} \mathrm{J}$ Cancer 93(9):1046-1052

8. Schnitt SJ, Guidi AJ (2004) Pathology of invasive breast cancer. In: Harris JR, Morrow M, Osborne CK, Lippman ME (eds) Diseases of the breast, 3rd edn. Lippincott, Williams \& Wilkins, Philadelphia

9. Qureshi HS, Linden MD, Divine G, Raju UB (2006) E-cadherin status in breast cancer correlates with histologic type but does not correlate with established prognostic parameters. Am J Clin Pathol 125(3):377-385

10. Le Gal M, Ollivier L, Asselain B, Meunier M, Laurent M, Vielh P, Neuenschwander S (1992) Mammographic features of 455 invasive lobular carcinomas. Radiology 185(3):705-708

11. Dillon MF, Hill AD, Fleming FJ, O'Doherty A, Quinn CM, McDermott EW, O'Higgins N (2006) Identifying patients at risk of compromised margins following breast conservation for lobular carcinoma. Am J Surg 191(2):201-205

12. Paumier A, Sagan C, Campion L, Fiche M, Andrieux N, Dravet F, Pioud R, Classe JM (2003) Évaluation de la validité du traitement conservateur dans le carcinome lobulaire infiltrant du sein: Á propos d'une étude rétrospective portant sur 217 carcinomes lobulaires infiltrants et 2155 carcinomes canalaires infiltrants. J Gynecol Obstet Biol Reprod (Paris) 32(6):529-534

13. Orel SG, Schnall MD (2001) MR imaging of the breast for the detection, diagnosis, and staging of breast cancer. Radiology 220(1):13-30

14. Ikeda DM, Hylton NM, Kinkel K, Hochman MG, Kuhl CK, Kaiser WA, Weinreb JC, Smazal SF, Degani H, Viehweg P, Barclay J, Schnall MD (2001) Development, standardization, and testing of a lexicon for reporting contrast-enhanced breast magnetic resonance imaging studies. J Magn Reson Imaging 13(6):889-895

15. Whiting PF, Weswood ME, Rutjes AW, Reitsma JB, Bossuyt PN, Kleijnen J (2006) Evaluation of QUADAS, a tool for the quality assessment of diagnostic accuracy studies. BMC Med Res Methodol 6:9

16. Corey DM, Dunlap WP, Burke MJ (1998) Averaging correlations: expected values and bias in combined Pearson rs and Fisher's z transformations. J Gen Psychol 125(3):245-261

17. Higgins JP, Thompson SG, Deeks JJ, Altman DG (2003) Measuring inconsistency in meta-analyses. BMJ 327 (7414):557-560

18. Bazzocchi M, Facecchia I, Zuiani C, Puglisi F, Di LC, Smania S (2000) Diagnostic imaging of lobular carcinoma of the breast: mammographic, ultrasonographic and MR findings. Radiol Med (Torino) 100(6):436-443

19. Boetes C, Veltman J, Van DL, Bult P, Wobbes T, Barentsz JO (2004) The role of MRI in invasive lobular carcinoma. Breast Cancer Res Treat 86(1):31-37

20. Cooney BS, Orel SG, Schnall MD, Troupin RH (1994) Invasive lobular carcinoma in a patient with synchronous ductal carcinoma in situ: detection with MR imaging. AJR Am J Roentgenol 162(6):1318-1320

21. Dalpiaz G, Zingarelli A, Anania G, Bazzocchi M (1996) Apporto della risonanza magnetica in un caso di adenocarcinoma lobulare della mammella. Radiol Med (Torino) 91(4):475-477

22. Diekmann F, Diekmann S, Beljavskaja M, Bick U, Taupitz M, Blohmer JU, Winzer KJ, Hamm B (2004) Präoperative MRT der Brust beim invasiv-lobulären im Vergleich zum invasiv-duktalen Karzinom. Rofo 176(4):544-549

23. Fabre Demard N, Boulet P, Prat X, Charra L, Lesnik A, Taourel P (2005) Apport de l'IRM dans le diagnostic et le bilan d'extension des cancers lobulaires infiltrants. J Radiol 86(9 Pt 1):1027-1034

24. Francis A, England DW, Rowlands DC, Wadley M, Walker C, Bradley SA (2001) The diagnosis of invasive lobular breast carcinoma. Does MRI have a role? Breast 10(1):38-40

25. Kepple J, Layeeque R, Klimberg VS, Harms S, Siegel E, Korourian S, Gusmano F, Henry-Tillman RS (2005) Correlation of magnetic resonance imaging and pathologic size of infiltrating lobular carcinoma of the breast. Am J Surg 190(4):623-627

26. Kneeshaw PJ, Turnbull LW, Smith A, Drew PJ (2003) Dynamic contrast enhanced magnetic resonance imaging aids the surgical management of invasive lobular breast cancer. Eur J Surg Oncol 29(1):32-37

27. Leung J, Kinkel K, Wang WL, Sickles EA, Hylton NM (2000) Morphologic and kinetic characteristics of lobular carcinoma of the breast at MR imaging. AJR Am J Roentgenol 174(Supplement):48

28. Munot K, Dall B, Achuthan R, Parkin G, Lane S, Horgan K (2002) Role of magnetic resonance imaging in the diagnosis 
and single-stage surgical resection of invasive lobular carcinoma of the breast. Br J Surg 89(10):1296-1301

29. Nokes SR, Pierce WB, Abraham DC, Harms SE (1999) Radiology. Infiltrating lobular carcinoma. J Ark Med Soc 96(5):176-177

30. Qayyum A, Birdwell RL, Daniel BL, Nowels KW, Jeffrey SS, Agoston TA, Herfkens RJ (2002) MR imaging features of infiltrating lobular carcinoma of the breast: histopathologic correlation. AJR Am J Roentgenol 178(5):1227-1232

31. Quan ML, Sclafani L, Heerdt AS, Fey JV, Morris EA, Borgen PI (2003) Magnetic resonance imaging detects unsuspected disease in patients with invasive lobular cancer. Ann Surg Oncol 10(9):1048-1053

32. Rodenko GN, Harms SE, Pruneda JM, Farrell RS Jr, Evans WP, Copit DS, Krakos PA, Flamig DP (1996) MR imaging in the management before surgery of lobular carcinoma of the breast: correlation with pathology. AJR Am J Roentgenol 167(6):1415-1419

33. Schelfout K, Van GM, Kersschot E, Verslegers I, Biltjes I, Leyman P, Colpaert C, Thienpont L, Van Den HJ, Gillardin JP, Tjalma W, Buytaert P, De SA (2004) Preoperative breast MRI in patients with invasive lobular breast cancer. Eur Radiol 14(7):1209-1216

34. Sittek H, Perlet C, Untch M, Kessler M, Reiser $M$ (1998) Dynamische MR-Mammographie beim invasive lobulären Mammakarzinom bei 1,0T. Rontgenpraxis 51(7): 235-242

35. Trecate G, Tess JD, Vergnaghi D, Bergonzi S, Mariani G, Ferraris C, Musumeci R (2001) Lobular breast cancer: how useful is breast magnetic resonance imaging? Tumori 87(4):232-238

36. Weinstein SP, Orel SG, Heller R, Reynolds C, Czerniecki B, Solin LJ, Schnall M (2001) MR imaging of the breast in patients with invasive lobular carcinoma. AJR Am J Roentgenol 176(2):399-406

37. Wilhelm K, Grebe P, Teifke A, Halbsguth A, Mitze M, Thelen M (1992) Das lobuläre Mammakarzinom in der Kernspintomographie. Aktuelle Radiol 2(6):373-375

38. Yeh ED, Slanetz PJ, Edmister WB, Talele A, Monticciolo D, Kopans DB (2003) Invasive lobular carcinoma: spectrum of enhancement and morphology on magnetic resonance imaging. Breast J 9(1):13-18

39. Bedrosian I, Mick R, Orel SG, Schnall M, Reynolds C, Spitz FR, Callans LS, Buzby GP, Rosato EF, Fraker DL, Czerniecki BJ (2003) Changes in the surgical management of patients with breast carcinoma based on preoperative magnetic resonance imaging. Cancer 98(3):468-473

40. Berg WA, Gutierrez L, NessAiver MS, Carter WB, Bhargavan M, Lewis RS, Ioffe OB (2004) Diagnostic accuracy of mammography, clinical examination, US, and MR imaging in preoperative assessment of breast cancer. Radiology 233(3):830-849

41. Kim SJ, Morris EA, Liberman L, Ballon DJ, La Trenta LR, Hadar O, Abramson A, Dershaw DD (2001) Observer variability and applicability of BI-RADS terminology for breast MR imaging: invasive carcinomas as focal masses. AJR Am J Roentgenol 177(3):551-557

42. Newstead G, Arkani S, Abe H, Schmidt R, Senett C, Yang C (2005) Dynamic breast MR imaging: comparison of kinetic and morphologic characteristics of malignant lesions by tumor type and grade. RSNA SSM01-05

43. Kneeshaw PJ, Turnbull LW, Drew PJ (2003) Role of magnetic resonance imaging in the diagnosis and single-stage surgical resection of invasive lobular carcinoma of the breast. Br J Surg 90(2):248

44. Tofts PS, Brix G, Buckley DL, Evelhoch JL, Henderson E, Knopp MV, Larsson HB, Lee TY, Mayr NA, Parker GJ, Port RE, Taylor J, Weisskoff RM (1999) Estimating kinetic parameters from dynamic contrast-enhanced T(1)-weighted MRI of a diffusable tracer: standardized quantities and symbols. $\mathbf{J}$ Magn Reson Imaging 10(3):223-232

45. Helvie MA, Paramagul C, Oberman HA, Adler DD (1993) Invasive lobular carcinoma. Imaging features and clinical detection. Invest Radiol 28(3):202-207

46. Hilleren DJ, Andersson IT, Lindholm K, Linnell FS (1991) Invasive lobular carcinoma: mammographic findings in a 10-year experience. Radiology 178(1):149-154

47. Paramagul CP, Helvie MA, Adler DD (1995) Invasive lobular carcinoma: sonographic appearance and role of sonography in improving diagnostic sensitivity. Radiology 195(1):231-234

48. Cornford EJ, Wilson AR, Athanassiou E, Galea M, Ellis IO, Elston CW, Blamey RW (1995) Mammographic features of invasive lobular and invasive ductal carcinoma of the breast: a comparative analysis. Br J Radiol 68(809):450-453

49. Krecke KN, Gisvold JJ (1993) Invasive lobular carcinoma of the breast: mammographic findings and extent of disease at diagnosis in 184 patients. AJR Am J Roentgenol 161(5): 957-960

50. Newstead GM, Baute PB, Toth HK (1992) Invasive lobular and ductal carcinoma: mammographic findings and stage at diagnosis. Radiology 184(3):623-627

51. Uchiyama N, Miyakawa K, Moriyama N, Kumazaki T (2001) Radiographic features of invasive lobular carcinoma of the breast. Radiat Med 19(1):19-25

52. Veltman J, Boetes C, van Die L, Bult P, Blickman JG, Barentsz JO (2006) Mammographic detection and staging of invasive lobular carcinoma. Clin Imaging 30(2):94-98

53. Cawson JN, Law EM, Kavanagh AM (2001) Invasive lobular carcinoma: sonographic features of cancers detected in a BreastScreen Program. Australas Radiol 45(1):25-30

54. Chapellier C, Balu-Maestro C, Bleuse A, Ettore F, Bruneton JN (2000) Ultrasonography of invasive lobular carcinoma of the breast: sonographic patterns and diagnostic value: report of 102 cases. Clin Imaging 24(6):333-336

55. Evans N, Lyons K (2000) The use of ultrasound in the diagnosis of invasive lobular carcinoma of the breast less than $10 \mathrm{~mm}$ in size. Clin Radiol 55(4):261-263

56. Rissanen T, Tikkakoski T, Autio AL, Apaja-Sarkkinen M (1998) Ultrasonography of invasive lobular breast carcinoma. Acta Radiol 39(3):285-291

57. Selinko VL, Middleton LP, Dempsey PJ (2004) Role of sonography in diagnosing and staging invasive lobular carcinoma. J Clin Ultrasound 32(7):323-332

58. Skaane P, Skjorten F (1999) Ultrasonographic evaluation of invasive lobular carcinoma. Acta Radiol 40(4):369-375

59. Pointon KS, Cunningham DA (1999) Ultrasound findings in pure invasive lobular carcinoma of the breast: comparison with matched cases of invasive ductal carcinoma of the breast. Breast 8(4):188-190

60. Drew PJ, Chatterjee S, Turnbull LW, Read J, Carleton PJ, Fox JN, Monson JR, Kerin MJ (1999) Dynamic contrast enhanced magnetic resonance imaging of the breast is superior to triple assessment for the pre-operative detection of multifocal breast cancer. Ann Surg Oncol 6(6):599 603 
61. Fischer U, Kopka L, Grabbe E (1999) Breast carcinoma: effect of preoperative contrast-enhanced MR imaging on the therapeutic approach. Radiology 213(3):881-888

62. Heywang-Kobrunner SH, Bick U, Bradley WG Jr, Bone B, Casselman J, Coulthard A, Fischer U, Muller-Schimpfle M, Oellinger H, Patt R, Teubner J, Friedrich M, Newstead G, Holland R, Schauer A, Sickles EA, Tabar L, Waisman J, Wernecke KD (2001) International investigation of breast MRI: results of a multicentre study (11 sites) concerning diagnostic parameters for contrast-enhanced MRI based on 519 histopathologically correlated lesions. Eur Radiol 11(4):531-546

63. Rieber A, Merkle E, Bohm W, Brambs HJ, Tomczak R (1997) MRI of histologically confirmed mammary carcinoma: clinical relevance of diagnostic procedures for detection of multifocal or contralateral secondary carcinoma. J Comput Assist Tomogr 21(5):773-779

64. Bluemke DA, Gatsonis CA, Chen MH, DeAngelis GA, DeBruhl N, Harms S, Heywang-Kobrunner SH, Hylton N, Kuhl CK, Lehman C, Pisano ED, Causer P, Schnitt SJ, Smazal SF, Stelling CB, Weatherall PT, Schnall MD (2004) Magnetic resonance imaging of the breast prior to biopsy. JAMA 292(22):2735-2742

65. Stoutjesdijk MJ, Futterer JJ, Boetes C, van Die LE, Jager G, Barentsz JO (2005) Variability in the description of morphologic and contrast enhancement characteristics of breast lesions on magnetic resonance imaging. Invest Radiol 40(6):355-362

66. Boetes C, Strijk SP, Holland R, Barentsz JO, Van Der Sluis RF, Ruijs JH (1997) False-negative MR imaging of malignant breast tumors. Eur Radiol 7(8):1231-1234

67. Korhonen T, Huhtala H, Holli K (2004) A comparison of the biological and clinical features of invasive lobular and ductal carcinomas of the breast. Breast Cancer Res Treat 85(1):23-29

68. Molland JG, Donnellan M, Janu NC, Carmalt HL, Kennedy CW, Gillett DJ (2004) Infiltrating lobular carcinoma-a comparison of diagnosis, management and outcome with infiltrating duct carcinoma. Breast 13(5):389-396

69. Lee AH, Dublin EA, Bobrow LG, Poulsom R (1998) Invasive lobular and invasive ductal carcinoma of the breast show distinct patterns of vascular endothelial growth factor expression and angiogenesis. J Pathol 185(4):394-401

70. Tresserra F, Feu J, Grases PJ, Navarro B, Alegret X, Fernandez-Cid A (1999) Assessment of breast cancer size: sonographic and pathologic correlation. J Clin Ultrasound 27(9):485-491

71. Watermann DO, Tempfer C, Hefler LA, Parat C, Stickeler E (2005) Ultrasound morphology of invasive lobular breast cancer is different compared with other types of breast cancer. Ultrasound Med Biol 31(2):167-174

72. Mersin H, Yildirim E, Gulben K, Berberoglu U (2003) Is invasive lobular carcinoma different from invasive ductal carcinoma? Eur J Surg Oncol 29(4):390-395

73. Kurtz JM, Jacquemier J, Torhorst J, Spitalier JM, Amalric R, Hunig R, Walther E, Harder F, Almendral A, Brandone H (1989) Conservation therapy for breast cancers other than infiltrating ductal carcinoma. Cancer 63(8):1630-1635

74. Sastre-Garau X, Jouve M, Asselain B, Vincent-Salomon A, Beuzeboc P, Dorval T, Durand JC, Fourquet A, Pouillart P (1996) Infiltrating lobular carcinoma of the breast. Clinicopathologic analysis of 975 cases with reference to data on conservative therapy and metastatic patterns. Cancer 77(1):113-120

75. Schnitt SJ, Connolly JL, Recht A, Silver B, Harris JR (1989) Influence of infiltrating lobular histology on local tumor control in breast cancer patients treated with conservative surgery and radiotherapy. Cancer 64(2):448-454

76. Morrow M, Keeney K, Scholtens D, Wei J, Steel J, Khan SA (2006) Selecting patients for breast-conserving therapy: the importance of lobular histology. Cancer 106(12):2563-2568

77. Vo TN, Meric-Bernstam F, Yi M, Buchholz TA, Ames FC, Kuerer HM, Bedrosian I, Hunt KK (2006) Outcomes of breast-conservation therapy for invasive lobular carcinoma are equivalent to those for invasive ductal carcinoma. Am J Surg 192(4):552-555

78. Santiago RJ, Harris EE, Qin L, Hwang WT, Solin LJ (2005) Similar long-term results of breast-conservation treatment for stage I and II invasive lobular carcinoma compared with invasive ductal carcinoma of the breast: the University of Pennsylvania experience. Cancer 103(12):2447-2454 